\title{
プロセス改善知識の形式化への取り組み
}

\section{Formalization of process improvement knowledge}

\author{
乘松聡 ${ }^{1}$, 遠藤潔 ${ }^{1 *}$, 臼杵誠 ${ }^{1}$, 丹羽愛一郎 ${ }^{1}$, 片山栄和 ${ }^{1}$, 橋本智博 ${ }^{1}$ \\ So NORIMATSU ${ }^{1}$, Kiyoshi ENDO ${ }^{1 *}$, Makoto USUGI ${ }^{1}$, Aiichiro NIWA ${ }^{1}$, Eiwa \\ KATAYAMA ${ }^{1}$, Tomohiro HASHIMOTO ${ }^{1}$
}

1 日本SPIコンソーシアム ソフトウェアプロセス改善知識網分科会

JASPIC : Japan Software Process Improvement Consortium

干171-8513 東京都豊島区南池袋2-32-8 (株)SRA 内

E-mail: contactA@jaspic.org

*連絡先著者 Corresponding Author

筆者らは,「日本SPIコンソーシアム(以降JASPIC)」の中で, プロセス改善に関する知識の体系化 に取り組んでいる. 当該ドメインにおける有用性の高い知識を蓄積し, 利用しやすい仕組みを提供 するとともに, 新たな知識の創出を促すことが狙いである. これまでのJASPIC主催の「SPI Japanカン ファレンス」における発表内容を知識として整理・集約する試みの中で, 知識の形式化の面, 特に網 羅性に問題があることが分かった. そこで, 当該ドメインにおける知識の表現形式として7つの情報要 素から構成される知識モデルを考案し, これを元に発表概要テンプレートとして標準化した. 結果と して, 知識の網羅性の分布に有意な変化が見られ, 原因分析・効果の検証・妥当性の確認に関する 記述量の増加が見られた. また, 知識の質の向上の観点からは, 発表の理解が容易になったという 良好なコメンド査読員やカンファレンス参加者から得られた.

The authors have been working within "Japan SPI Consortium (JASPIC)" towards establishment of a knowledge structure for process improvement. Our objective is to store useful knowledge, to provide mechanisms for its usage, and to encourage creation of new knowledge. During our efforts to extract, categorize and consolidate knowledge from the presentation materials at the "SPI Japan" conferences organized by JASPIC, we saw problems with respect to the formalization of knowledge, especially its coverage. To solve this issue, we devised a knowledge model that consists of seven information elements as a representation of domain specific knowledge, and then introduced a standard template to be used for presentation abstract. As a result, statistically significant change in the distribution of knowledge coverage was observed, and the amount of descriptions increased for items such as causal 
analysis, verification and validation of process improvement. In terms of improvement for the quality of knowledge, positive feedbacks were obtained from proposal reviewers and conference participants for improved understandability.

キーワード: プロセス改善, 知識の形式化, 知識の表現形式, テンプレートによる標準化, 知識の網羅性 Keyword: process improvement, formalization of knowledge, representation of knowledge, standardization by template, coverage of knowledge

\section{1 プロセス改善ドメインの特質}

筆者らが所属する日本SPIコンソーシア ムでは，「ソフトウェアプロセス改善 Software Process Improvement (SPI)」と 呼ばれる改善活動によってQCD (Q：Quality 品質，C：Costコスト，D：Delivery納期） を向上させることを目指して，改善事例の 共有を行っている $[1]$.

このドメインでは, ソフトウェア開発プ ロセスという，一般的な製造プロセスより も人間による作業が多く含まれる対象を 扱うため, 一般的な工学原理を適用する際 の再現可能性が低いという特徵が見られ る.

そのため，ある組織や部署における改善 事例を他のケースに適用した場合でも，同 一の成果が得られるとは限らない。同様に, 一つの改善事例に対する類似環境での比 較事例を特定することも難しいため, 報告 された改善事例における知見が確かに有 効であるという確証も得にくいという問 題もある。

蓄積された経験事例群を再利用する上 では, 自分たちの環境(組織・対象プロセ ス)において既存の知識を適用することが 可能であるかを判断する必要がある. しか し，これまで報告された事例においては必 要な情報が不足しているために，このよう な判断が難しい場合が多かった.

\section{2 プロセス改善の7つのステップ}

\section{1 プロセス改善活動の一般的な構造}

プロセス改善事例に含まれる情報の網 羅性を議論するための出発点として, プロ セス改善活動の一般的な構造を図1のよう に整理した。

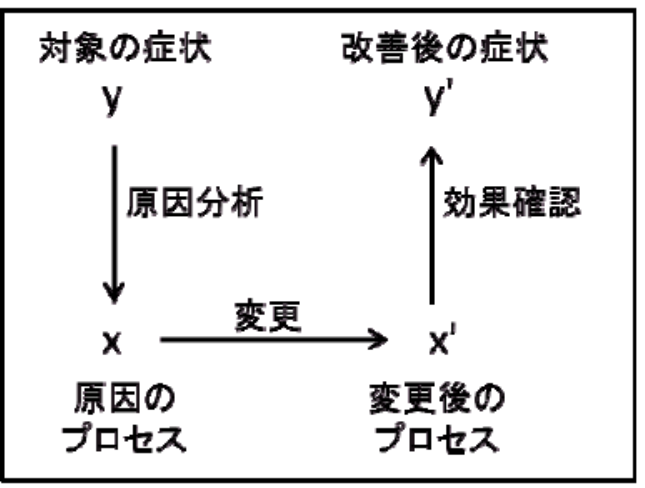

図 1 プロセス改善活動の一般的な構造

図1の中で, yやy’ は改善前後の状態 (観 測される事象), $\mathrm{x}$ や’ セス(原因となる事象)である，すなわち， プロセス改善活動を俯瞰的に定義すると,

「望ましい結果(y’)を得るために，原因 となるプロセス $\mathrm{x}$ )を変更すること」であ ると言える。

一般に, 改善活動では, 改善対象となる 症状の特定からスタートする。

例えば，「完成したソフトウェアに含ま 
れる欠陥が多い」という状態がyに相当す る. 最終的に, yに含まれる問題が解決し た状態がy'である. yからy’に至る過程を 7 つのステップに 分解すると, 以下のようになる.

(1)y : 改善前の状態

改善の対象となる状況や問題・症状を特 定し, y’への期待を明らかにする.

(2) $\mathrm{y} \rightarrow \mathrm{x}$ : 改善前の状態をもたらした原因 (因果関係)

yという状態をもたらしている主要な事 象や原因 (例えば, 特定のプロセス) とし てのxを特定する.

(3) $\mathrm{x}$ : 変更前のプロセス xに関する情報を集め, 分析する. 実際 には, ステップ(2)と(3)が試行的もしくは 再帰的に繰り返される場合が多い.

(4) $\mathrm{x} \rightarrow \mathrm{x}^{\prime}$ : 変更内容・対応策 xを制御・変更するための変更点や原因 への対応策を特定する. x’の内容だけで なく, 必要となる作業の特定を含む.

(5) $x^{\prime}$ :変更後のプロセス x'を実行する.

(6) $\mathrm{x}^{\prime} \rightarrow \mathrm{y}^{\prime}$ : 変更後の効果

変更後の状態y' を測定し, $\mathrm{x} \rightarrow \mathrm{x}^{\prime}$ の効果 が得られたことを検証する.

(7)y' : 改善後の状態

改善策を全体として分析し, 改善策の妥 当性, 費用対効果, 残存課題や副次効果 を確認する。

これら7つの情報はそれぞれに有用な知 見を含んでいることが多く, 単体として知 識として呼ぶこともできるであろう。しか し, 改善活動を実践して確実な成果を得る ためには，これらの全ての要素が正しく組 み合わされている必要がある. その意味で,
これら7つの要素が揃ったひとまとまりが 「改善活動における知識単位」であり, こ れら 7 つの要素が改善知識の表現形式で ある。

\section{2 改善事例の報告例}

以下に， 7 つのテップに基づく改善事 例の報告例として,「完成したソフトウェ アに含まれる欠陥が多い」ことを解決する ためのテストプロセス改善事例を示す.

例 1 : 期待される報告の例

(1)：「欠陥の流出が多い」。陥数 (現 状)を測定し，目標値を設定した.

(2) : 欠陥の流出原因を分析し，テストプ ロセスの不十分性(テストケースの網羅性 が低い)を特定した。

(3) : 現状のテストプロセス・実施状況を 明確にした. 境界值テストの欠落を特定し た(状況を確認した).

(4) : プロセス上の課題(境界値テストの 欠落原因=テストケース設定方針が不明 確・周知されていない, テス卜設計者のス キル不足などから，主に設定方針の曖昧さ があること)を明らかにし，変更点として， 境界值テストの強化を含む設定方針の明 確化とトレーニングの強化を行うことに した.

(5)：変更点を反映 $($ 方針を記述・トレー ニングを実施) した後, 新プロセスを実行 した. 工夫点として, トレーニング後の確 認テストを行い, 結果が悪いメンバに対し ては合格するまで追加トレーニングを実 施したことが挙げられる.

(6) : 変更後のプロセスを実施した結果と して，境界値テストが実施され，境界値の 欠陥が検出されていることを確認した.さ 
らに実際の製品に流出した欠陥数が低減 したことを確認した.

(7) : 設定した目標值に対する達成度を確 認した. 欠陥が流出した場合の対応工数と 比べて, 新プロセス実行のための工数が少 ないため, 費用対効果が高いことを確認し た.

当コンソーシアムで主催しているカン ファレンス(SPI Japanカンファレンス)で の経験事例の報告では, 上記の 7 つの情報 が網羅されていない場合が散見された．例 えば例 2 に示すようなケースでは, 分析が 不十分であり, また, 改善効果の確実性に 関する検証が行われていない. そのため, 他の組織において同様の改善策を実施す ることが適切であるかを判断することが 難しく, 結果として知識の再利用性が低く なってしまう。

例 2 : 情報が不足している報告の例(説 明のための架空のケース)

(1) : 品質が問題となり, 他社よりも欠陥 が多いことが指摘された.

(2) : 欠陥の流出原因を分析し，テストケ ースの数が少ないことが判明した.

(3)：(記述なし)

(4)：(記述なし)

(5) : テストケースのレビューを強化した. 特に若手とベテランのペアで実施した.

(6) : レビューによってテストケースが追 加され，2倍になった.

(7) : 若手の満足度が上がった. 今後もテ ストケースレビューを実施したい.

\section{3 標準テンプレートの変更}

7 つのステップからなる改善知識の表 現形式を基準にして経験情報を集めるた めに, SPI Japanカンファレンスでの事例 発表の形式を標準化することにした.

従来, 当該カンファレンスにおける一般 発表では, A4版2ページ程度 (1000文字以 上)の発表概要が提出され, 有用性および 信頼性に関して複数の查読員による査読 が行われていた. その結果採択されたもの が，カンファレンス当日に発表されていた. 発表概要の指定フォーマットでは, 「背景, 課題, 内容 (着想や創案など), 効果」につ いて記載することが指定されていた.

2013年度のカンファレンスでは, この指 定フォーマットを 7 のステップに基づい て修正し, より詳細な項目を指定すること で, 記述形式の標準化を目指した.

標準テンプレートでは，7つのステップ の項目を以下のように再編成し，7つの章 から成る基本構成にしている.

・活動に取り組んだ動機, 本来の大きな 目的，前提などを記載する「背景」欄 を追加

・ステップ(2)と(3)を統合

・各章ごとに記載が期待される追加情報 を指定

実際に使用したテンプレートの主要部 分の抜粋を図 2 に示す. 図 2 のの部分が上 記の追加情報の項目に該当する. 
(1) 背景

৯本発表の対象となる活動に取り組んだ動機, 本来の大きな目的, 前提など

(2) 改善前の状態

太改善の対象として取り上げた状況や問題・症状.

ネおよび,それを選んだ理由.

（3）改善前の状態をもたらした原因（因果関係）

れ改善前の状態をもたらしていると最終的に判断した事象や原因（例えば, あるプロセス）.一つ以上の事象や原因が関連している場合もある.

ネおよび, それらの事象・原因を洗い出し・選定・特定した方法.

(4) 変更内容・対応策

太事象の変更内容や, 原因への対応策. 変更には, 「既存のものを変える」

「既存のものを廃止する」「新しいことを追加する」等の場合を含む.

ネおよび,それらを選んだ理由.

(5) 変更や対応策の実施内容

太変更や対応策を実現するための具体的な活動.

ネおよび, 工夫した点や, 苦労した点.

(6) 変更・改善後の状態と効果

れ変更や対応策を実施したことによる変化状況（状態）

太(2)の「改善対象として取り上げた状況や問題・症状」の変化状況（効果）

丸および，(可能な限り）効果が偶然ではないことの検証結果.

（7）改善活動の妥当性確認

太改善活動を全体として分析し, 改善策の妥当性, 費用対効果, 残存課題,

副次効果などを確認した結果

図 2 標準テンプレートの主要部分(抜粋)

事例を募集する際には, 独自の章の追加 や，適用が難しい事例の場合の標準からの 逸脱も認めたが，ほとんどの事例が標準テ, ンプレートをそのまま使用していた[2].

\section{4 テンプレートの導入効果}

\section{1 知識の網羅性の評価方法}

標準テンプレートの導入の効果を評価

するために, 導入前後での知識の網羅性の
比較評価を行った.

ここでの知識の網羅性とは, 以下の二つ の属性から定義される.

充実度 : 指定された推奨項目 (13個)の記 述量. 項目ごとに記述の十分性 $(O \Delta \times)$ を 測定し， 1 点・ 0.5 点・0点で定量化したも のの合計点. 13 点満点.

網羅度 : 指定された章立て (7個)の記述 量. 章ごとに最初の推奨項目が十分に記述 されていれば，その章が記述されていると 
みなして1点を与える. 全章についての合 計点. 7 点満点.

テンプレート導入の前後として，2011年 度と 2013 年度のカンファレンスを選択し た. それぞれの応募事例から無作為に25個 ずつを抽出し，5名の評価者が5個ずつの事 例を評価した。評価者間のバラツキを最小 化するために, 同一事例を複数メンバで評 価して評価点のバラツキの程度を測定し, 判断基準の調整を行っている.

\section{2 網羅性の評価結果(全体傾向)}

2011年度の応募事例の評価結果の分布 を図3に示す。

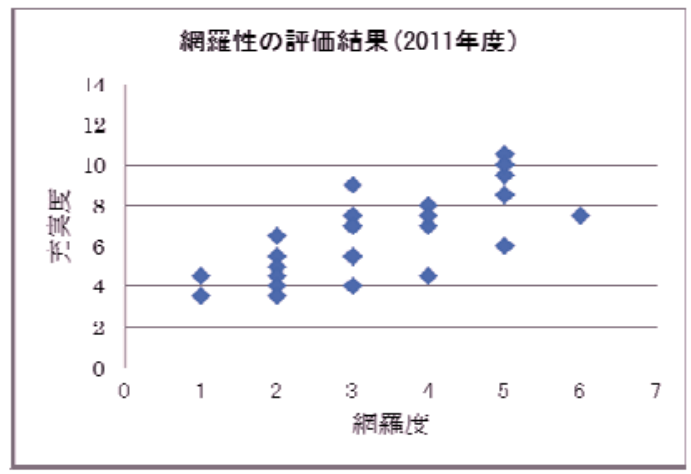

図 32011 年度分の網羅性の評価結果

網羅度の平均値は3.24 (7点満点), 充実 度の平均值は 6.50 (13点満点)であった. 期 待する情報量の概ね $50 \%$ 程度であることが 分かる.

2013年度の応募事例の評価結果の分布 を図4に示す。

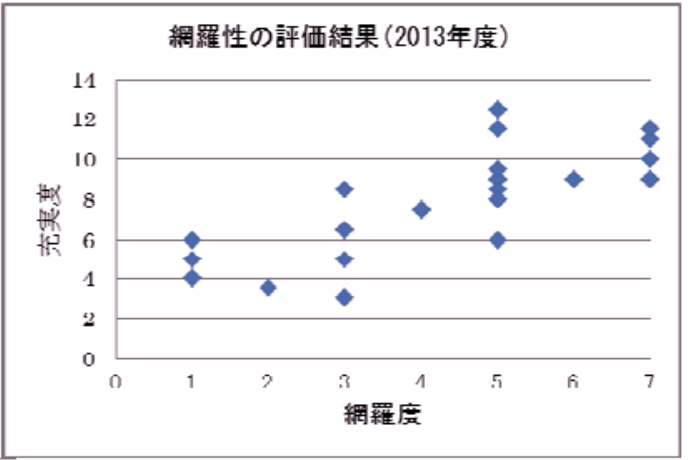

図 42013 年度分の網羅性の評価結果

網羅度の平均值は 4.32 , 充実度の平均 值は 7.80 であったので，それぞれ 15\%， 10\%の向上が見られた.

これらの結果の統計量を表 1 に示す.

表 1 網羅性の記述統計量(年度比較)

\begin{tabular}{|l|c|c|}
\hline & 2011 年度 & 2013 年度 \\
\hline 網羅度 & \multicolumn{2}{|c|}{} \\
\hline 平均と,その & $3.24(46 \%)$ & $4.32(62 \%)$ \\
$95 \%$ 信頼区間 & $2.67-3.81$ & $3.55-5.09$ \\
\hline 標準偏差 & 1.39 & 1.86 \\
\hline 充実度 & \multicolumn{2}{|l|}{} \\
\hline 平均と,その & $6.50(50 \%)$ & $7.80(60 \%)$ \\
95\%信頼区間 & $5.65-7.34$ & $6.76-8.84$ \\
\hline 標準偏差 & 2.05 & 2.51 \\
\hline
\end{tabular}

さらに, これらの変化を統計的に分析 した結果を表 2 に示す.

表 2 網羅性の比較の検定統計量

\begin{tabular}{|c|c|c|}
\hline & 2011 年度 & 2013 年度 \\
\hline 網羅度 & \multicolumn{2}{|c|}{} \\
\hline 正規性 & $\mathrm{p}=0.0680$ & $\mathrm{p}=0.0186$ \\
\hline 等分散性 & \multicolumn{2}{|c|}{$\mathrm{p}=0.1602$} \\
\hline $\mathrm{t}$ 検定 & \multicolumn{2}{|c|}{$\mathrm{p}=0.0246$} \\
\hline Welch 検定 & \multicolumn{2}{|c|}{$\mathrm{p}=0.0250$} \\
\hline Wilcoxon 検定 & \multicolumn{2}{|c|}{$\mathrm{p}=0.0262$} \\
\hline 充実度 & \multicolumn{2}{|c|}{} \\
\hline 正規性 & $\mathrm{p}=0.3775$ & $\mathrm{p}=0.4875$ \\
\hline 等分散性 & \multicolumn{2}{|c|}{$\mathrm{p}=0.3214$} \\
\hline $\mathrm{t}$ 検定 & \multicolumn{2}{|c|}{$\mathrm{p}=0.0505$} \\
\hline Welch 検定 & \multicolumn{2}{|c|}{$\mathrm{p}=0.0507$} \\
\hline Wilcoxon 検定 & \multicolumn{2}{|c|}{$\mathrm{p}=0.0542$} \\
\hline
\end{tabular}


正規性 (Shapiro-Wilk の正規性検定に よる)については，2013 年度の網羅度の 正規性が棄却される. 原因は不明だが, 指定した項目間の依存関係によるものか も知れない.

等分散性(両側 $\mathrm{F}$ 検定による)の検定結 果は, 充実度に関しては等分散と言える.

分散分析により平均值の変化の有意性 を評価すると，網羅度については Wilcoxon 検定で $\mathrm{p}=0.026$ となり，有意な 変化と言える．充実度については，t 検 定では $\mathrm{p}=0.05$ に近く，有意水準 0.05 で は有意とは言えないものの, 一定の変化 が見られたことが分かった.

\section{3 網羅性の評価結果(個別項目)}

さらに，以前から記述不足の傾向が見 られた以下の項目について, 記述の有無 がどのように変化したかの評価を行った.

(1)原因分析に関する記述

(2)効果の検証に関する記述

(3)改善の妥当性の記述

比較結果を表 3 に示す.

表 3 記述量の平均値の比較

\begin{tabular}{|l|l|l|l|}
\hline & 2011 & 2013 & (比率) \\
\hline 原因分析 & 0.54 & 0.68 & $(1.26)$ \\
\hline 効果検証 & 0.06 & 0.12 & $(2.00)$ \\
\hline 妥当性確認 & 0.12 & 0.40 & $(3.33)$ \\
\hline
\end{tabular}

全般的に, 当初問題視されていた項目に ついて網羅性の向上が見られるが，まだ全 体としては満足できる水準とはなってい ない.

\section{5 知識の質の向上}

知識の網羅性を向上させる目的は, 利用 可能性や有用性を含む「知識の質」を向上 させることにある，現時点では，評価方法 を含めて研究中の段階であり, 質の向上を 定量的に確認するには至っていない.

定性的な感想としては, 查読が容易にな ったという意見や，発表を整理したり，内 容を理解したりすることが容易になった という意見が査読員やカンファレンス参 加者から得られた. これらは表現形式の標 準化の効果でもあり，また情報量が増えた ことによる効果であるとも推定される。

\section{6 結論と今後の課題}

プロセス改善事例をカンファレンスで 収集する際に, 改善知識の構造を形式化し, その表現形式を元に発表概要テンプレー 卜を標準化した。それにより，発表に含ま れる知識の平均網羅度は $46 \%$ から $62 \%$ ，平均 充実度は $50 \%$ から $60 \%$ へと向上した. 特に, 課題となっていた情報項目については, 1. 3 3. 3倍の記述量の改善が見られた. 全 体として，コミュニティとしての情報収集 の精度が向上したと言える.

今後は, テンプレートの記載要領や項目 の改良を通じて収集精度をさらに高める 必要がある.すなわち，今回のようなデー タスキーマとしてのオントロジーを元に, 知識共有の媒体としての活用を進める必 要がある [3]．また，そもそも事例に含ま れる知識の情報量や有用性を向上させる 努力も必要であろう. 将来的には, プロセ ス改善知識をオントロジーとして体系化 することを目指している。 


\section{謝辞}

本論文は，日本SPIコンソーシアム

(JASPIC)の「ソフトウェアプロセス改善知 識網分科会」活動の一環で作成されたもの です. 活動を支援して下さったJASPIC分科 会推進チームに感謝いたします. また, 本 論文における「発表概要テンプレート」の 運営および活用にご協力いただいた, SPI JAPAN 2013の運営スタッフと2013年発表応 募者の皆様に感謝いたします. さらに, 本 論文作成のための議論に参加いただいた 方々，特に水田 恵子氏に感謝いたします。 最後になりましたが, 本論文を受理してい ただいた情報知識学会の皆様に感謝いた します.

\section{参考文献}

[1] Ogasawara, Hideto: "Status of SPI Activities in Japanese Software - A view from JASPIC", Industrial Proceedings, EuroSPI2013 (European Systems Software \& Service Process Improvement \& Innovation), pp.8.21 - 8.30.

[2] 日本SPIコンソーシアム:「SPI Japan 2013 発表概要集」, 東京, 2013, 日本SPI コンソーシアム, http://www.jaspic.org/event/2013/SPIJapan/ab stracts/abstracts.zip

[3] 來村 徳信：「オントロジーの普及と 応用」, 第一版, 東京都, オーム社, $238 \mathrm{p}$. , 2012. 